disorders in general (Farooq et al, 2005). Studies of this kind should promote better awareness and understanding among trainees of the importance of carrying out proper risk assessment and management. Substantial resources also need to be invested in order to restructure the whole system.

\section{References}

Farooq, S. (2001) Psychiatric training in developing countries. British Journal of Psychiatry, 179, 464.
Farooq, S., Akhtar, J., Anwar, E., et al (2005) The attitude and perception of hospital doctors about the management of psychiatric disorders. Journal of the College of Physicians and Surgeons Pakistan, 15, 552-555.

Haider, I. S. \& Haider, I. (2001) Deliberate self harm. Pakistan Journal of Medical Sciences, 17, 151-155.

Karim, S., Saeed, K., Rana, M. H., et al (2004) Pakistan mental health country profile. International Review of Psychiatry, 16, 83-92.

Khan, M. M. (1998) Suicide and attempted suicide in Pakistan. Crisis, 19, 172-176.

Khan, M. M., Islam, S. \& Kundi, A. K. (1996) Parasuicide in Pakistan: experience at a university hospital. Acta Psychiatrica Scandinavica, 93, 264-267.

\title{
The psychological and psychosocial impact of the Pakistan Kashmir earthquake after 8 months: a preliminary evaluation by PACTT
}

\author{
PACTT: Pakistan-Aberdeen Collaborative Trauma Team*
}

$\mathrm{N}$ atural disasters are complex events that challenge the coping abilities of individuals and communities (Alexander, 2005). They are characterised by substantial loss, physical injury and economic hardship, as well as by extensive internal displacement and damage to the infrastructure, as exemplified by the Pakistan Kashmir earthquake of 8 October 2005. Measuring 7.6 on the Richter scale, it affected an area of 30000 square miles and a population of 3.6 million. Approximately 90000 were killed, 200000 were injured and 3.5 million were left homeless (Khan, 2006). Based on a literature review and estimates from the World Health Organization (WHO), the National Plan of Action for Mental Health and Psychosocial Relief of Earthquake Survivors anticipated high levels of trauma-related psychopathology (Rana et al, 2006).

A disaster of such magnitude poses enormous problems for mental health and psychosocial care (Ghodse \& Galea, 2006), particularly in the context of high levels of untreated pre-earthquake morbidity in Pakistan (Mirza \& Jenkins, 2004) plus the estimated post-earthquake morbidity (Rana et al, 2006). The absence of evidence-based 'best practice' for culturally sensitive psychological interventions in relation to such a disaster led to a miscellany of unintegrated interventions being implemented in the earthquake-affected region (Khan, 2006). The blanket provision of such interventions is not a cost-effective or efficient strategy and may even be harmful (Alexander, 2005).

Fundamental to informing a culturally sensitive disaster response strategy is an epidemiological and needs assessment approach (van Ommeren et al, 2005), but post-disaster ethical, methodological and logistic factors may impede the use of representative sampling methods and culturally validated instruments (Klein \& Alexander, 2007).

To test the feasibility of undertaking a culturally informed, epidemiological, community-based survey of the traumatic effect of the earthquake, the Pakistan-Aberdeen Collaborative Trauma Team (PACTT) conducted a pilot study in the earthquake-affected region of Azad Jammu and Kashmir (AJ\&K). A key objective of the pilot was to test the acceptability of the assessment instruments in terms of their cultural and linguistic sensitivity (e.g. with regard to symptom expression), length, comprehensibility and process of administration. Assessment instruments comprised a trauma-modified version of the Composite International Diagnostic Interview (CIDI-TM) developed by PACTT and the Screening Instrument for Traumatic Stress in Earthquake Survivors (SITSES; Basoglu et al, 2001). This paper reports on the outcome of that evaluation and presents preliminary findings derived from the SITSES in relation to the psychological and psychosocial impact of the Pakistan Kashmir disaster after 8 months.

*PACTT consists of the following members: Pakistan - Brigadier Mowadat H. Rana, ${ }^{1}$ Dr Sohail Ali, ${ }^{2}$ Dr Babur Yusufi ${ }^{3}$;

Aberdeen, Scotland, UK - Professor David A. Alexander, ${ }^{4}$ Dr Susan Klein, ${ }^{5}$ Professor Amanda J. Lee, ${ }^{6}$ Dr Gareth T. Jones, ${ }^{7}$ Professor Gary Macfarlane ${ }^{8}$ ${ }^{1}$ Advisor in Psychiatry, Military Hospital Rawalpindi; ${ }^{2}$ Consultant Psychiatrist, Military Hospital Rawalpindi; ${ }^{3}$ Specialist Registrar, Community Learning Disability Service, Mile End Hospital, London; ${ }^{4}$ Director, Aberdeen Centre for Trauma Research, The Robert Gordon University, Aberdeen;

${ }^{5}$ Reader, Aberdeen Centre for Trauma Research, The Robert Gordon University, Aberdeen; ${ }^{6}$ Professor of Medical Statistics, Department of General Practice and Primary Care, University of Aberdeen; ${ }^{3}$ Senior Lecturer in Epidemiology, Epidemiology Group, Department of Public Health, School of Medicine, University of Aberdeen; 'Professor of Epidemiology, Epidemiology Group, Department of Public Health, School of Medicine, University of Aberdeen Corresponding author: Dr S. Klein, Reader, Aberdeen Centre for Trauma Research, Faculty of Health and Social Care, The Robert Gordon University, Scotland, UK, email s.klein@rgu.ac.uk 


\section{Methods}

Conducted in May 2006, this 1-month pilot study was based on a convenience sample of 112 consenting adult survivors (aged 18 years and older) selected from camps in the three AJ\&K districts of Muzaffarabad, Rawalakot and Bagh (the major earthquake-affected regions). For pragmatic reasons, families within each district were identified with the assistance of the Imam Masjid (religious leader of the area) and the head teacher of the local school. A statement of confidentiality was read by the interviewer before each face-to-face interview.

\section{Assessment}

As an earthquake-specific instrument, the SITSES was included in the assessment to enable comparisons with studies of survivors of a Turkish earthquake with features similar to those experienced in Pakistan Kashmir (e.g. the scale of devastation and number of casualties, as well as the resource-poor environment). The SITSES was translated into Urdu according to the specifications of the WHO translation protocol, and administered face to face by 14 trained lay interviewers (eight of whom were female). Familiar with the local community and bilingual in English and Urdu, each interviewer completed a workshop on standardised interview techniques conducted by WHO certified trainers.

The SITSES comprises three sections:

The 28-item Survivor Information Form (SIF) records socio-demographic characteristics, and the features of the earthquake and its effect on survivors (including severity of disability, the nature and level of the loss experienced in relation to family, possessions and livelihood, and fear experienced at the time of the earthquake).

O The Traumatic Stress Symptom Checklist (TSSC) comprises ratings for 17 DSM-IV symptoms of post-traumatic stress disorder (PTSD) and six depressive symptoms, for the diagnosis of PTSD and comorbid depression, respectively. All symptoms are assessed in relation to the past week, on a four-point scale $(0=$ 'not bothered', 1 = 'slightly bothered', 2 = 'fairly bothered', 3 = 'very much bothered'). Validated by Basoglu et al (2001), against the Clinician-Administered PTSD Scale (CAPS; Blake et al, 1990) and the major depressive episode module of the Structured Interview for DSM-IV (SCID; First et al, 1996), the TSSC has high internal consistency and satisfactory sensitivity and specificity in predicting the diagnosis of PTSD and major depression. The recommended optimal cut-off point of 25 and above for the total score based on the 17 PTSD symptoms was used to identify PTSD. The optimal cut-off point of 38 and above for the total score calculated from the 23 TSSC items determined the presence of comorbid depression.

The Severity of Disability Scale, comprising just two items, measures the global severity of stress resulting from the symptoms reported in the TSSC in relation to work, family and social functioning, using the same four-point scale.

\section{Analysis}

Data were analysed by the Statistical Package for the Social Sciences (SPSS for Windows; version 14.0). A two-tailed $P<0.05$ denoted statistical significance. Due to skewed distributions and/or heterogeneity of variance, non-parametric methods, including the Mann-Whitney $U$ and chi-square tests, were applied.

\section{Results}

\section{Sample characteristics}

Satisfactory data were available on 111 of the 112 individuals sampled (99.1\%). The median age of the sample was 34 years (interquartile range, $I Q R=25-45.25$ ) and $50 \%$ were female. The median number of children per family was $3(\mathrm{IQR}=2-6)$. The socio-demographic and health profile of participants is shown in Table 1. A family history of mental illness was reported by $11.8 \%(n=13 / 110)$ and $5.6 \%$ $(n=6 / 108)$ reported a personal history of mental illness requiring treatment before the earthquake.

\section{Impact of the earthquake}

Of those who had been in a building at the time of the earthquake, a quarter $(n=15 / 60)$ reported that they had been trapped under rubble. Most participants $(82.7 \%, n=91 / 110)$ rated the intensity of fear or terror experienced during the earthquake as either 'severe' or 'extremely severe'. Over half (56.4\%, $n=62 / 110$ ) of the sample participated in rescue work. Table 2 shows the impact of the earthquake in terms of physical injury sustained, loss of life and loss of property.

Table 1 Socio-demographic and health profile of the participants

\begin{tabular}{|c|c|c|}
\hline & $n$ & $\%$ \\
\hline \multicolumn{3}{|l|}{ Marital status $(n=111)$} \\
\hline Single (never married) & 22 & 19.6 \\
\hline Married & 75 & 67.9 \\
\hline Widowed & 11 & 9.8 \\
\hline Separated & 2 & 1.8 \\
\hline Divorced & 1 & 0.9 \\
\hline \multicolumn{3}{|l|}{ Level of education $(n=110)$} \\
\hline No schooling, illiterate & 40 & 36.4 \\
\hline No schooling, literate & 7 & 6.4 \\
\hline Primary school & 19 & 17.3 \\
\hline Secondary school & 21 & 19.1 \\
\hline High school & 20 & 18.2 \\
\hline University/postgraduate studies & 3 & 2.7 \\
\hline \multicolumn{3}{|l|}{ Employment status $(n=110)$} \\
\hline Employed & 30 & 27.3 \\
\hline Self-employed & 10 & 9.1 \\
\hline Looking for work & 14 & 12.7 \\
\hline Temporarily laid off & 5 & 4.5 \\
\hline Retired & 2 & 1.8 \\
\hline Housewife & 25 & 22.7 \\
\hline Student & 8 & 7.3 \\
\hline Disabled & 2 & 1.8 \\
\hline Never worked & 5 & 4.5 \\
\hline Other & 6 & 5.5 \\
\hline Refused to answer & 3 & 2.7 \\
\hline \multicolumn{3}{|c|}{ Rating of current overall physical health $(n=108)$} \\
\hline Excellent & 11 & 10.1 \\
\hline Very good & 10 & 9.2 \\
\hline Good & 32 & 30.3 \\
\hline Fair & 31 & 28.4 \\
\hline Poor & 24 & 22.0 \\
\hline \multicolumn{3}{|c|}{ Rating of current overall mental health $(n=108)$} \\
\hline Excellent & 6 & 5.6 \\
\hline Very good & 15 & 13.9 \\
\hline Good & 33 & 30.6 \\
\hline Fair & 27 & 25.0 \\
\hline Poor & 27 & 25.0 \\
\hline \multicolumn{3}{|c|}{ Rating of overall health compared with 1 year ago $(n=106)$} \\
\hline Much better now & 5 & 4.7 \\
\hline Somewhat better now & 6 & 5.7 \\
\hline About the same & 19 & 17.9 \\
\hline Somewhat worse now & 50 & 47.2 \\
\hline Much worse now & 25 & 23.6 \\
\hline Refused to answer & 1 & 0.9 \\
\hline
\end{tabular}


Table 2 Earthquake-specific characteristics and experience of the participants

\begin{tabular}{|c|c|c|c|}
\hline & $n$ & $\begin{array}{l}\text { Sample } \\
\text { size }\end{array}$ & $\%$ \\
\hline \multicolumn{4}{|l|}{ Suffered serious physical injury } \\
\hline Family member(s) & 33 & 104 & 31.7 \\
\hline Relative(s) & 43 & 110 & 39.1 \\
\hline \multicolumn{4}{|l|}{ Witnessed serious physical injury of: } \\
\hline Relative(s) & $\begin{array}{l}23 \\
19\end{array}$ & $\begin{array}{l}30 \\
29\end{array}$ & 48.7 \\
\hline \multicolumn{4}{|l|}{ Death of: } \\
\hline Family member(s) & 45 & 110 & 40.9 \\
\hline Relative(s) & 59 & 103 & 57.3 \\
\hline Friend(s) and/or neighbour(s) & 84 & 109 & 77.1 \\
\hline \multicolumn{4}{|l|}{ Witnessed death of: } \\
\hline Family member(s) & 20 & 44 & 45.5 \\
\hline Relative(s) & 22 & 61 & 36.1 \\
\hline Friend(s) and/or neighbour(s) & 46 & 108 & 42.6 \\
\hline $\begin{array}{l}\text { Witnessed others being seriously } \\
\text { injured or killed }\end{array}$ & 90 & 111 & 81.1 \\
\hline \multicolumn{4}{|l|}{ Loss of property } \\
\hline Personal possessions & 79 & 101 & 78.2 \\
\hline Land & 3 & 101 & 3.0 \\
\hline Animals & 4 & 101 & 4.0 \\
\hline Vehicles & 1 & 101 & 1.0 \\
\hline Business & 1 & 101 & 1.0 \\
\hline Other & 11 & 101 & 10.9 \\
\hline Refused to answer & 2 & 101 & 2.0 \\
\hline
\end{tabular}

Table categories are mutually exclusive.

Following the earthquake, $46.8 \%$ of participants ( $n=36 / 77$ ) relocated to a different region.

\section{Estimated prevalence of PTSD and comorbid depression}

Eight months after the earthquake, the prevalence rates of PTSD and comorbid depression were $46.8 \%(n=52 / 111)$ and $27.9 \%(n=31 / 111)$, respectively. A significant gender difference was found: women were approximately twice as likely as men to have PTSD $\left(64.4 \%\right.$ versus $37.8 \% ; \chi^{2}=6.40$, d.f. $=1$, $P=0.011)$ and four times more likely to have comorbid depression (48.9\% v. $11.1 \% ; \chi^{2}=15.29$, d.f. $\left.=1, P<0.001\right)$. Women reported significantly more overall distress ( median $=2, \mathrm{IQR}=1.5-4 \mathrm{v}$. median $=3, \mathrm{IQR}=2-4 ; P=0.02$ ) but no significant gender difference was observed for functional impairment (median $=2, \mathrm{IQR}=1-2.5 \mathrm{v}$. median $=2$, $\mathrm{IQR}=1-3 ; P=0.52)$. Thirty-six participants $(39.6 \%, n=91)$ wanted help from a psychiatrist or psychologist for the psychological and psychosocial problems experienced after the earthquake; no significant difference was found between men and women in this regard $(P=0.179)$.

\section{Discussion}

Disasters are unpredictable events which pose obvious methodological challenges, particularly with regard to identifying a representative sampling frame for the at-risk population (Klein \& Alexander, 2007). Because of the limitations associated with selected survival and population movement, the absence of accurate and reliable figures to enumerate and characterise the affected population in Pakistan Kashmir resulted in our reliance on a convenience sample for this pilot. While this sampling method precludes precise generalisation to the affected population and findings should be interpreted accordingly, our preliminary evaluation based on the SITSES suggests the significant and enduring psychological and psychosocial sequelae of a major natural disaster. The substantial loss sustained as a result of the earthquake included loved ones and personal property. A high level of physical injury was experienced, both personally and by family members and relatives. Following the earthquake, many relocated to a different region.

The high prevalence of PTSD (46.8\%) and comorbid depression (27.9\%) are comparable to the gender-adjusted rates reported for the 1000 Turkish survivors of $43 \%$ and 31\%, respectively, after 3-10 months (Basoglu et al, 2002). That women were more likely than men to report post-traumatic symptoms is a consistent observation from community-based epidemiological studies (Klein \& Alexander, 2006).

Three-quarters of the sample reported that their overall health had deteriorated substantially compared with 1 year before the earthquake. Despite community-based population prevalence rates of 34\% for anxiety and depressive disorders derived from a systematic review of studies conducted in Pakistan before the earthquake (Mirza \& Jenkins, 2004), few reported a personal history of mental illness requiring treatment before the earthquake. This finding may reflect the stigma attached to mental illness by those who are uneducated and live in the more rural areas, including AJ\&K, and where mental health facilities are not accessible for geographical, financial and cultural reasons (Karim et al, 2004). Alternatively, it may derive from cultural and individual differences in how psychological distress is interpreted, how it is expressed and to what it is attributed (Klein \& Alexander, 2007). While this study did not assess the underlying reasons for the non-reporting of medical symptoms of distress and associated treatment, the finding that a third of those who reported emotional problems after the earthquake wanted help from a mental health professional may suggest that the collective experience of the disaster, including participation in this pilot study, helped to reduce that stigma.

Key outcomes of this pilot study included confirmation of the acceptability and cultural sensitivity of the Urdu translation of the SITSES for administration to the target population and the need for further modification of the CIDI-TM in terms of substantially reducing its overall length, revising the core PTSD module and simplifying the logic for ease of administration by the interviewers. With regard to issues relating to the socio-cultural and religious sensitivities of the target population, the reliable assessment of substance misuse was particularly problematic, as evidenced by the high number of refusals obtained for this module.

Overall, this pilot was invaluable in terms of informing the design of a culturally informed epidemiological survey as the first step in enabling the evaluation of a delayed programme (to allow for the natural remission of post-traumatic reactions) of community-based and culturally appropriate psychosocial interventions, delivered by trained grass-roots personnel. This unique research programme constitutes a systematic scientific endeavour to promote conceptual clarity and evidence-based practice in the long-term management of disaster survivors and is in accordance with the WHO's policy on mental health and psychosocial support for disaster victims (van Ommeren et al, 2005). 


\section{Acknowledgements}

We thank all the master trainers, interviewers, senior trainees and consultant psychiatrists (Department of Psychiatry, Military Hospital, Rawalpindi) for their substantial contribution and all those earthquake survivors for their invaluable participation in this pilot study. We also thank Professor Kessler (Co-director of the WHO World Mental Health Survey Initiative) and Dr Basoglu for their assistance in relation to the CIDI-TM and SITSES.

\section{References}

Alexander, D. A. (2005) Early mental health intervention after disasters. Advances in Psychiatric Treatment, 11, 12-18.

Basoglu, M., Salcioglu, E., Livanou, M., et al (2001) A study of the validity of a screening instrument for traumatic stress in earthquake survivors in Turkey. Journal of Traumatic Stress, 14, 491-509.

Basoglu, M., Salcioglu, E. \& Livanou, M. (2002) Traumatic stress responses in earthquake survivors in Turkey. Journal of Traumatic Stress, $15,269-276$

Blake, D. D., Weathers, F. W., Nagy, L., et al (1990) A clinician rating scale for assessing current and lifetime PTSD: the CAPS-1. Behavior Therapist, 13, 187-188.
First, M. B., Spitzer, R. L., Gibbon, M., et al (1996) Structured Clinical Interview for DSM-IV Axis I Disorders - Non-patient Edition (SCIP-I/NP, Version 2). New York State Psychiatric Institute, Biometrics Research Department.

Ghodse, H. \& Galea, S. (2006) Tsunami: understanding mental health consequences and the unprecedented response. International Review of Psychiatry, 18, 289-297.

Karim, S., Saeed, K., Rana, M. H., et al (2004) Pakistan mental health country profile. International Review of Psychiatry, 16, 83-92.

Khan, M. M. (2006) Earthquake 2005: challenges for Pakistani psychiatry. International Psychiatry, 3, 21-23.

Klein, S. \& Alexander, D. A. (2006) Epidemiology and presentation of post-traumatic disorders. Psychiatry, 5, 225-227.

Klein, S. \& Alexander, D. A. (2007) Post-disaster research issues. In The Day the Mountains Moved: Earthquake in Pakistan (ed. U. Niaz), pp. 233-263. SAMA Editorial and Publishing Services.

Mirza, I. \& Jenkins, R. (2004) Risk factors, prevalence, and treatment of anxiety and depressive disorders in Pakistan: systematic review. BMJ, 328, 794.

Rana, M. H., Ali, S., Yusufi, B., et al (2006) National Plan of Action for Mental Health and Psychosocial Relief of Earthquake Survivors - emergency phase. Pakistan Armed Forces Medical Journal, 56, 402-411.

van Ommeren, M., Saxena, S. \& Saraceno, B. (2005) Aid after disasters. BMJ, 330, 1160-1161.

\title{
Traditional health practitioners and mental health in Kenya
}

\author{
Marx Okonji, ${ }^{1}$ Frank Njenga, ${ }^{2}$ David Kiima, ${ }^{3}$ James Ayuyo, ${ }^{4}$ Pius Kigamwa,, \\ Ajit Shah ${ }^{6}$ and Rachel Jenkins
}

${ }^{1}$ Consultant Psychiatrist, Chiromo Lane Medical Centre, Nairobi; ${ }^{2}$ Consultant Psychiatrist, Chiromo Lane Medical Centre, Nairobi; ${ }^{3}$ Director of Mental Health, Ministry of Health, Afya House, Nairobi, Kenya; ${ }^{4}$ Mildmay International, Kisumu, Kenya; ${ }^{5}$ Lecturer, University of Nairobi School of Medicine, Nairobi, Kenya; ${ }^{6}$ Professor of Ageing, Ethnicity and Mental Health, Institute for Philosophy, Diversity and

Mental Health, University of Central Lancashire, Preston, UK;

7Director of the WHO Collaborating Centre, Institute of Psychiatry, De Crespigny Park, London SE5 8AF, UK, email rachel@olan.org

hep

he prevalence of psychiatric morbidity among rural and urban Kenyan primary care attenders has been reported to be as high as 63\% (Ndetei \& Muhangi, 1979; Dhapdale \& Ellison, 1983; Dhapdale et al, 1989; Sebit, 1996). For its population of 32 million, Kenya has only 16 psychiatrists and 200-300 psychiatric nurses, but there are just over 2000 primary healthcare centres, staffed by general nurses and clinical officers, and the main burden for assessing and caring for people with mental disorders falls upon members of the primary care teams. However, mental disorders are poorly recognised (Dhapdale \& Ellison, 1983) and inadequately treated in primary care (Muluka \& Dhapdale, 1986). Moreover, Kenyan primary care workers often lack training in mental health (Dhapdale et al, 1989; see also Ndetei, this issue, p. 31).

In contrast to this picture of poor recognition and treatment of mental disorders in primary care, people with mental disorders commonly consult traditional health practitioners (THPs) in African countries, including South Africa (Zabow, 2007), Nigeria (Olugbile et al, 2007), Tanzania (Ngoma et al, 2003) and Kenya (Ndetei, 2007). Around 50\% of Kenyans who consult THPs may have psychiatric morbidity (Ndetei, 2007) and many use both modern medical services and
THPs simultaneously (Odejide et al, 1978; Ndetei, 2007). In neighbouring Tanzania, the prevalence of common mental disorders among those consulting THPs is high (Ngoma et al, 2003), reflecting the failure of primary care services to detect and treat these disorders adequately. Patients may go to hospitals to seek a cure for their illness, and go to THPs to seek both cure and explanation (Otsyula, 1973), particularly if they are not satisfied with modern medical services (Katz \& Kimani, 1982). Therefore, this paper reports a qualitative study to examine the views of THPs in Kenya pertaining to the nature, aetiology, symptoms and classification of mental illness, as well as treatment approaches, in order to establish whether there is an adequate shared conceptual basis for further dialogue and liaison.

\section{Methods}

\section{Sample}

The sample frame was all 70 THPs either registered with $(n=47)$ or otherwise known to $(n=23)$ Kisumu District Cultural and Social Services Office as practising in the Maseno Division, a poor rural area of 50000 population. All 70 THPs 